\title{
Crystalline Mixed Halide Halobismuthates and Their Induced Second Harmonic Generation
}

Xiaoxin Zheng, Yang Liu*, Guangfeng Liu, Jie Liu, Xin Ye, Quanxiang Han, Chao

Ge, and Xutang Tao*

State Key Laboratory of Crystal Materials, Shandong University, Jinan 250100, P. R. China

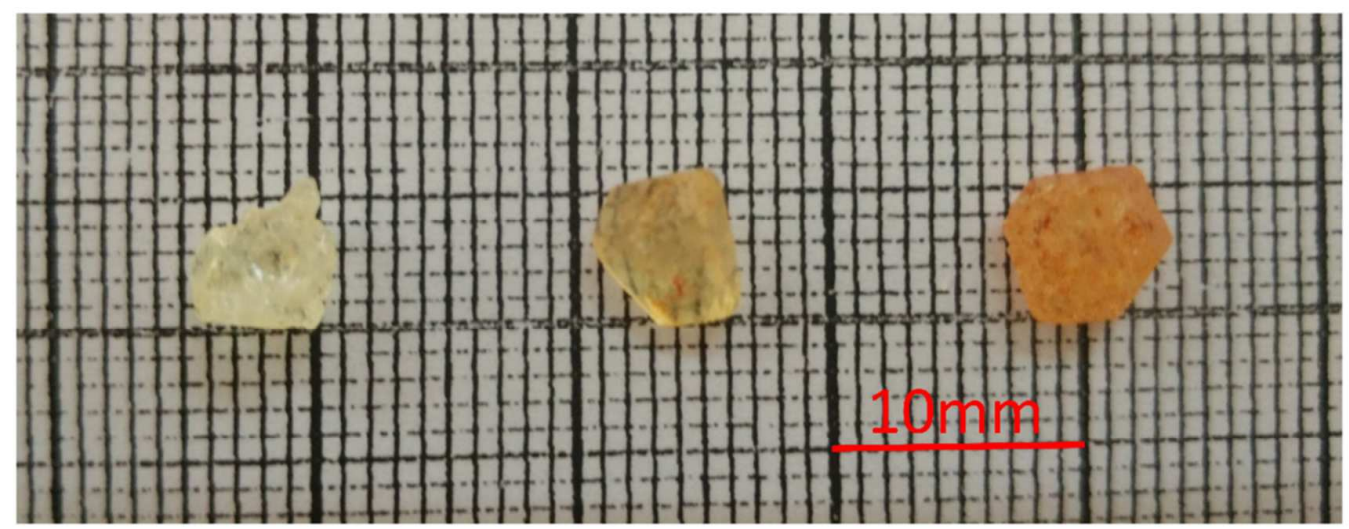

Figure $\mathbf{S 1}$ Single crystal of $\left[\mathrm{NH}_{2}\left(\mathrm{CH}_{2} \mathrm{CH}_{3}\right)_{2}\right]_{3} \mathrm{Bi}\left(\mathrm{Cl}_{1-\mathrm{x}} \mathrm{Br}_{\mathrm{x}}\right)_{6}(\mathrm{x}=0.255,0.847,1)$. 


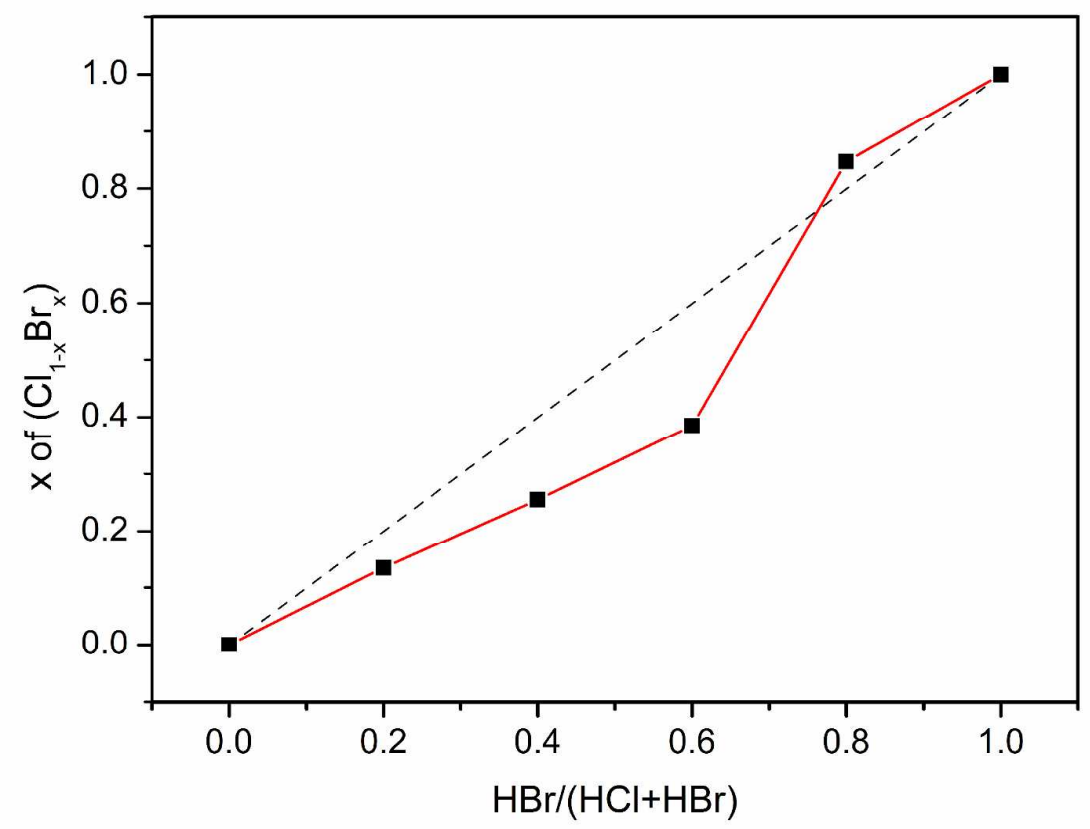

Figure S2. The $\mathrm{x}$ of $\left(\mathrm{Cl}_{1-\mathrm{x}} \mathrm{Br}\right)$ in $\left[\mathrm{NH}_{2}\left(\mathrm{CH}_{2} \mathrm{CH}_{3}\right)_{2}\right]_{3} \mathrm{Bi}\left(\mathrm{Cl}_{1-\mathrm{x}} \mathrm{Br}_{\mathrm{x}}\right)_{6}(\mathrm{x}=0,0.135,0.255,0.385,0.847,1)$ single crystals crystallized from different halogen concentrations in the precursor solvents.

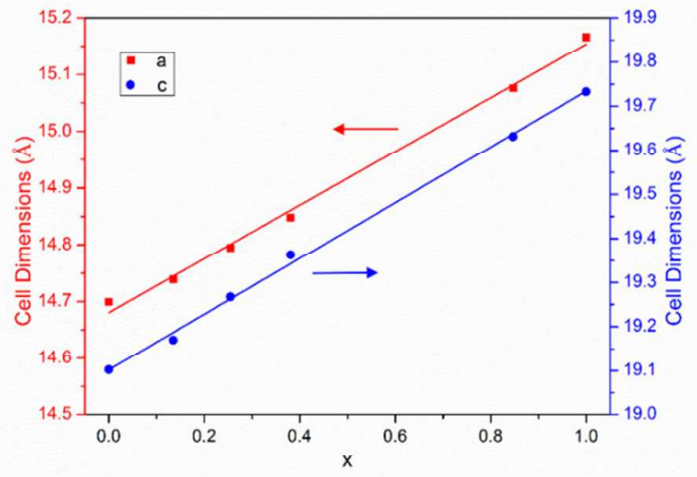

(a)

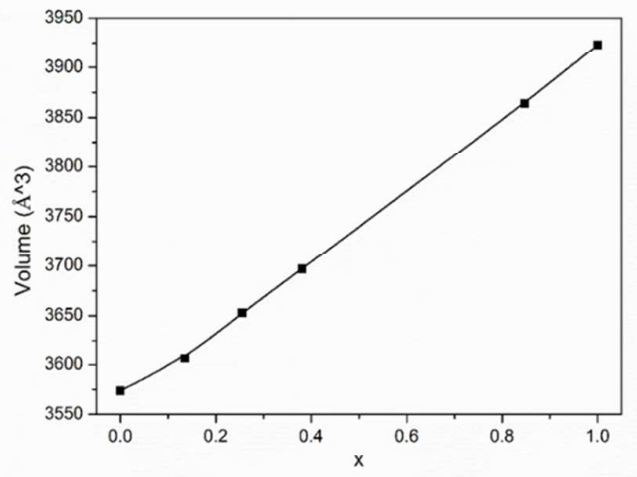

(b)

Figure S3. The single crystal XRD cell dimensions (a) and volumes (b) of $\left[\mathrm{NH}_{2}\left(\mathrm{CH}_{2} \mathrm{CH}_{3}\right)_{2}\right]_{3} \mathrm{Bi}\left(\mathrm{Cl}_{1-\mathrm{x}} \mathrm{Br}_{\mathrm{x}}\right)_{6}(\mathrm{x}=0,0.135,0.255,0.385,0.847,1)$ as a function of bromine inclusion. 


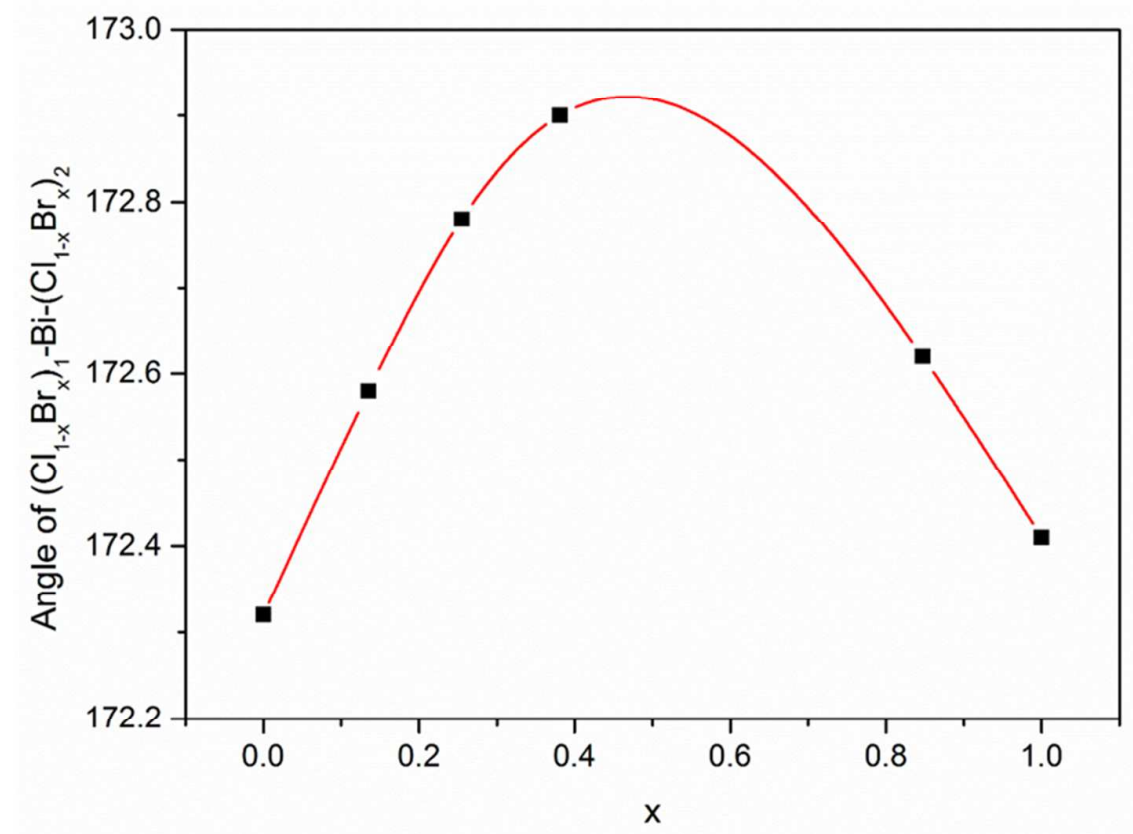

Figure $\mathrm{S4}$. The bond angle of $\left(\mathrm{Cl}_{1-\mathrm{x}} \mathrm{Br}_{\mathrm{x}}\right)_{1}-\mathrm{Bi}-\left(\mathrm{Cl}_{1-\mathrm{x}} \mathrm{Br}_{\mathrm{x}}\right)_{2}$ in $\left[\mathrm{NH}_{2}\left(\mathrm{CH}_{2} \mathrm{CH}_{3}\right)_{2}\right]_{3} \mathrm{Bi}\left(\mathrm{Cl}_{1-\mathrm{x}} \mathrm{Br}_{\mathrm{x}}\right)_{6}(\mathrm{x}=0,0.135$, $0.255,0.385,0.847,1)$ as a function of bromine.

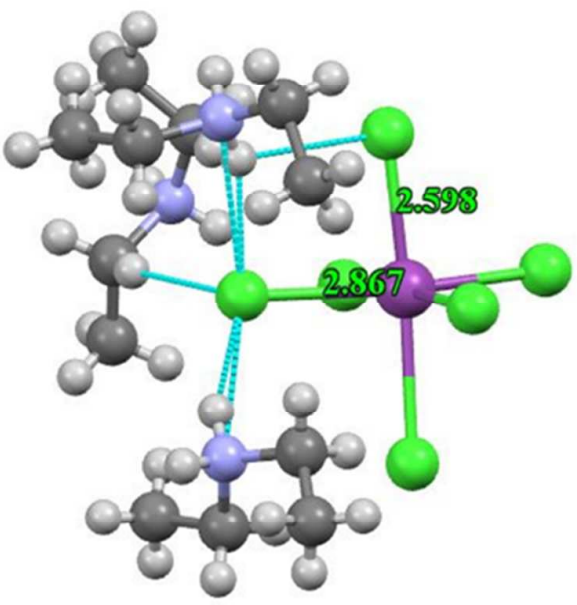

$\mathrm{x}=0$ 

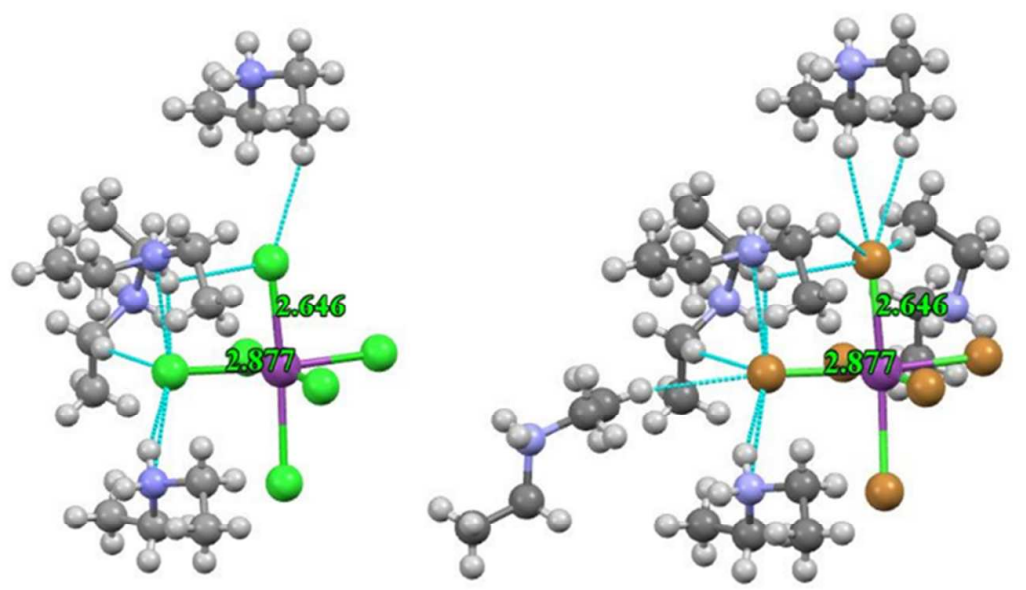

$x=0.135$
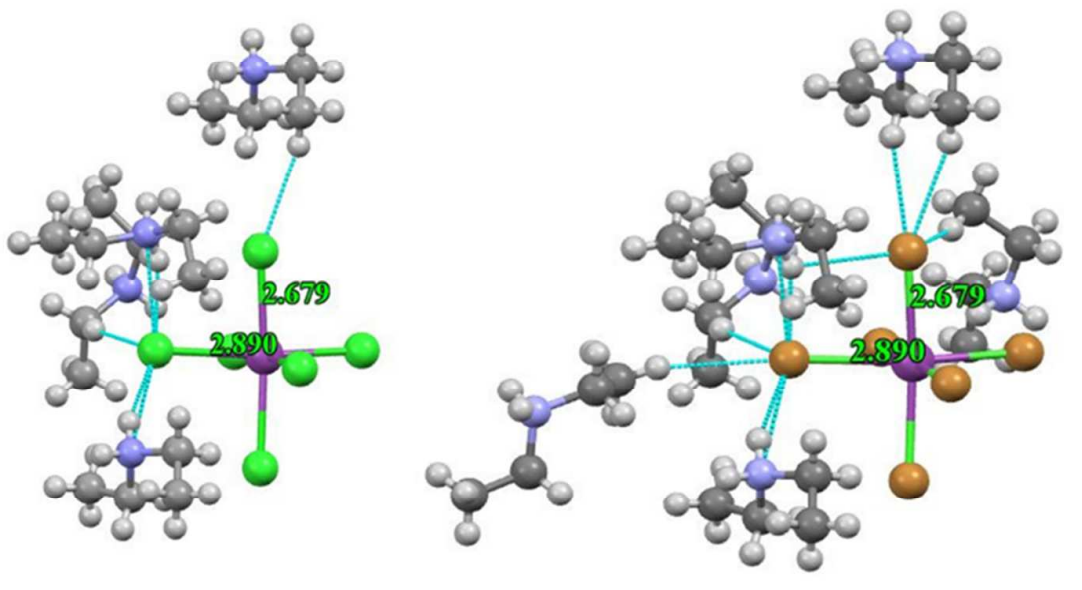

$x=0.255$ 

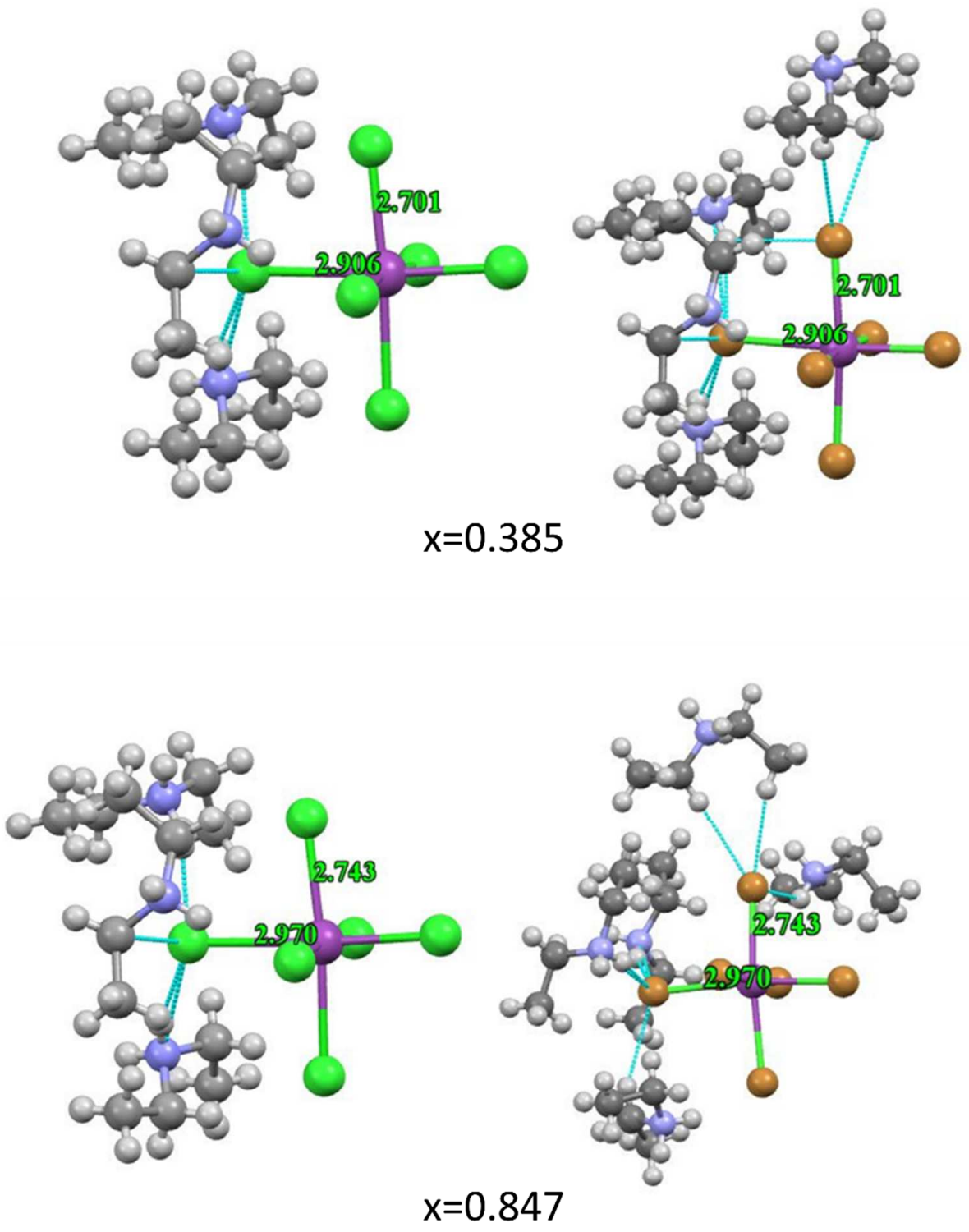


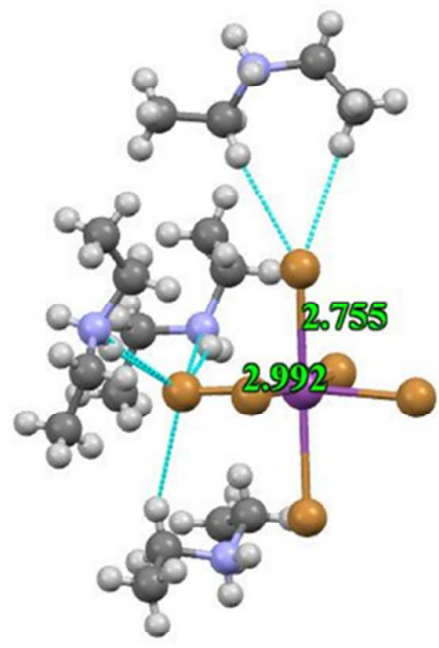

\section{$x=1$}

Figure S5. Interactions between $\mathrm{Bi}\left(\mathrm{Cl}_{1-\mathrm{x}} \mathrm{Br}_{\mathrm{x}}\right)_{6}{ }^{3-}$ anions and diethylammonium cations of various $\left[\mathrm{NH}_{2}\left(\mathrm{CH}_{2} \mathrm{CH}_{3}\right)_{2}\right]_{3} \mathrm{Bi}\left(\mathrm{Cl}_{1-\mathrm{x}} \mathrm{Br}_{\mathrm{x}}\right)_{6}(\mathrm{x}=0,0.135,0.255,0.385,0.847,1)$ crystal structures. Color scheme: $\mathrm{Bi}$ (III), purple; $\mathrm{Cl}$, green; $\mathrm{Br}$, brown; $\mathrm{C}$, grey; $\mathrm{N}$, blue; $\mathrm{H}$, white. 